\title{
Using Mobile ICT for Online Learning During COVID-19 Lockdown
}

\author{
Viktoriia Tkachuk $^{1}$ (D), Yuliia Yechkalo ${ }^{1}$ (D), Serhiy Semerikov ${ }^{1,2,3(\bowtie)}(\mathbb{D})$ \\ Maria Kislova ${ }^{4}$ (D), and Yana Hladyr $^{1}$ (D)
}

${ }^{1}$ Kryvyi Rih National University, 11 Vitalii Matusevych Street, Kryvyi Rih 50027, Ukraine hladyr@knu.edu.ua

2 Kryvyi Rih State Pedagogical University, 54 Gagarin Avenue, Kryvyi Rih 50086, Ukraine

3 Institute of Information Technologies and Learning Tools of NAES of Ukraine,

9, M. Berlynskoho Street, Kyiv 04060, Ukraine

4 Separated Structural Subdivision "Kryvyi Rih Professional College of National Aviation University”, 1 Tupolev Street, Kryvyi Rih 50045, Ukraine

kislova1975@ukr. net

\begin{abstract}
The research is aimed at theoretical substantiation, development and experimental verification of methods of applying mobile technologies to university students training during the COVID-19 lockdown. The research objective implies adapting mobile ICT to online learning during the COVID-19 lockdown. There are analyzed Ukrainian and foreign researches into the issues of mobile ICT application to the University students training. The authors have developed methods of applying Audience Response Systems by taking Plickers as an example; Mobile Multimedia Authoring Tools development through using augmented reality; Mobile Learning Management Systems by taking Moodle; Mobile Modeling and Programming Environments through using Pydroid; Mobile Database Management Systems by taking Google Cloud SQL. There is comparative assessment of functionality of five systems of mobile ICT for online learning during the COVID-19 lockdown. Efficiency of the developed technology is experimentally verified and confirmed.
\end{abstract}

Keywords: Online learning · Mobile ICT · Mobile Learning Management System · Mobile Modeling and Programming Environments · Mobile Database Management Systems · Mobile Multimedia Authoring Tools · Audience Response Systems · COVID-19 lockdown

\section{Introduction}

There are developed and introduced new strategies of online teaching and learning, support and service structures, which often call for system-related changes at universities. Relying on central elements of distance learning in practice and theory, the authors [6] apply new opportunities of ICT - from multimedia training objects to social, combined media and the virtual environment - to online learning. L. M. Blaschke and S. Bedenlier 
elaborated a teaching guide and practical instructions for teachers to develop and carry out educational software and courses online.

Online tools [33] are a means of improving qualifications of university teachers and instructors of higher vocational education. The tools are aimed at improving teachers' abilities to use innovative teaching methods and develop syllabuses for online learning on the basis of digital training materials and tools including open educational resources.

L. Mishra, T. Gupta and A. Shree [31] note that the educational system, from the primary to the higher one, changed during the COVID-19 lockdown. The research presents qualitative and qualitative approaches to studying teachers' and students' perception of online learning. The authors focus on overcoming obstacles in learning and enhancing online academic activity as a standard procedure within the educational system.

The authors [11] accentuate the fact that wrong ergonomics of a working place including that at home hides long-term consequences for health. During the COVID-19 lockdown, students stayed at home, this leading to their dependence on online classes, workshops and meetings. The research conducted evaluates impacts of ergonomic conditions on students who have to spend more time with gadgets. The research reveals that both students and teachers were not aware of ergonomics and did not observe ergonomic rules during the two-month lockdown. As a result, many of them developed serious problems that might cause a variety of health complications in future. There arises a necessity to include the issues of ergonomics and working place arrangement into the curricula.

- Many countries have issued the documents to regulate academic activity during the COVID-19 lockdown, including:

- Guidance for all schools in England "Restricting attendance during the national lockdown: schools" [34];

- Guidance on distance learning modalities to reach all children and youth during school closures by UNICEF Regional Office for South Asia [19];

- Helping children and young people while they are learning at home by New Zealand Ministry of Education [22];

- Teaching and learning during the quarantine: changes in the educational system by the Ministry of Education and Science of Ukraine [48];

- Coronavirus: online learning resources: Discover a selection of online resources and tools for learners, teachers and educators during the outbreak of COVID-19 by European Commission [14];

- Colleges, Universities, and Higher Learning: Plan, Prepare and Respond - COVID-19 by U.S. Department of Health \& Human Services [12];

- Coronavirus (COVID-19) information for higher education providers by Department of Education, Skills and Employment of Australian Government [13].

Application of mobile technologies in online education was the issue for investigation in works by M. E. Jantjies [24] and F. Fotouhi-Ghazvini [17] (in teaching languages); S. O. Semerikov [40] (in teaching Computer Sciences); A. Abu-Al-Aish [1], S. S. Baharom [3], P. W. Bird [5], C. Billington [4], M. Hepburn [23], J. J. Trinder [47] and E. A. Wali [49] (in the tertiary education system); Y. Shao [41] (in open education); V. Jotham [25] and N. N. Chan [8] (in everyday life). 
ICT alters both teaching and learning by adding active elements to the academic environment and is considered as a powerful tool for providing academic services. Nowadays, researchers think that the educational system is capable of improving only when ICT is implemented. At schools, colleges and universities, the staff use technology to execute their duties including technical, office, managerial, administrative, etc. Computer literacy is one of the basic skills when applying for a lecturer's position besides teaching qualifications and skills. Thus, we can state that ICT has contributed much to improving general conditions of the academic environment [26].

ICT cover all aspects of social life and play an important part in education by motivating, encouraging acquisition of basic skills and changing the academic environment, thus improving education quality. ICT possesses a great educational potential through making teachers updated and dynamic. It also enriches students' educational experience and promotes their future career in the technological world [43].

In the paper [10] presents the results of comparative analysis of the academic content designed for mobile devices, special attention being paid to the issues affecting mobile learning, i.e. its duration, systemacy, complexity, aims and structure. It is proven that the mobile content is better structured than the content of other educational media and a critical evaluation is offered for the content type to be developed.

Research [39] aims to provide quantitative analysis of ICT's impacts on students' mobility and motivation in the professional context by various criteria: the level of implementation and practicality of mobile technologies; an organizational system; a degree of mobility, motivation and application of ICT to the professional context, individual efficiency. The results reveal that creation of the organizational system with ICT enables increase of mobility. Besides, the organizational system that enhances mobility at work also increases motivation.

In paper [45] we have analyzed the latest publications on the following tools:

- Mobile Learning Management Systems (L. Sanz-Martínez et al. [38], V. Bykov [7], I. Han and W. S. Shin [21]);

- Mobile Modeling and Programming Environments (B. Altayeb and K. Damevski [2], F.-J. Lordan Gomis [28]);

- Mobile Database Management Systems (D.M. Gezgin [18], M. Guo et al. [20], M. Eric et al. [16]);

- Mobile Multimedia Authoring Tools (Yu. Yechkalo et al. [50], D. Tjondronegoro [44], A. Striuk et al. [42]);

- Audience Response Systems (T.F.I. Chan et al. [9], D.M. Moorleghen et al. [32]).

\section{Application of Mobile ICT to Training}

\subsection{Methods of Applying Audience Response Systems}

Tools of monitoring, controlling and assessing academic results are some of mobile software ICT types.

While monitoring the maturity level of students' ICT competences, there are applied various monitoring tools with the testing control of knowledge being a priority. Audience Response Systems are tools for assessing students' academic results [36, 37, 39]. 
Audience Response Systems are a variety of mobile software support aimed to measure students' academic results that enables automatizing the process of current and final control through applying modern testing tools and intensifying students' learning due to:

- ensuring mobility, cost effectiveness (efficiency) and privacy of testing through developing and implementing the technology of storing and using a short-term session of transmitting test assignments from the Internet server by wireless connection means;

- solving the problem of constraints in terms of technical characteristics and distance differentiation of teachers' and students' computers during a testing session arrangement [35].

Audience Response Systems aligning with this definition include ClassMarker, EasyTestMaker, Google Forms, iSpring QuizMaker, Kahoot!, MyTestXpro, Plickers, ProProfs, etc.

In our research, we distinguish the Audience Response System Plickers as the one providing an opportunity to arrange a rapid feedback between a teacher and an academic group including individual students; conducting a mobile survey, in-class general questioning and instant control of students' attendance. This system is beneficial in terms of high efficiency as it is very time-consuming and availability of students' smartphones or computers is not obligatory as a teacher's mobile device will do.

Plickers can be used in various operating systems of fixed computers and mobile devices. The system is meant for up to 63 students tested simultaneously. The system is noted for instant scanning of students' responses by a teacher's mobile device. The system also enables viewing students' testing results (both of a group as a whole and each student separately) in the form of a table.

To work with Plickers, a University teacher should get registered on the site (https:// www.plickers.com/) and compile a library of tests on a variety of subjects.

During testing, students are provided with cards with QR-codes (https://www.pli ckers.com/PlickersCards_2up.pdf) containing response options A, B, C, and D (Fig. 1). After reading a question, students raise a card with a chosen response scanned by a teacher's mobile device.
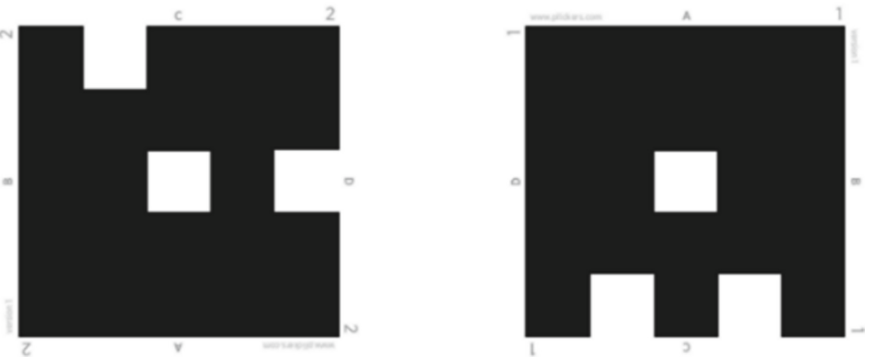

Fig. 1. Plickers cards with QR-codes. 
After scanning QR-codes of the cards, the data from the teacher's mobile device is transmitted to the Plickers cloud where they are processed and stored. Plickers enables either analysis of individual students' results or a general characteristic of a student group's statistics. Students' use Plickers cards in Informatics class at Kryvyi Rih National University (Fig. 2).

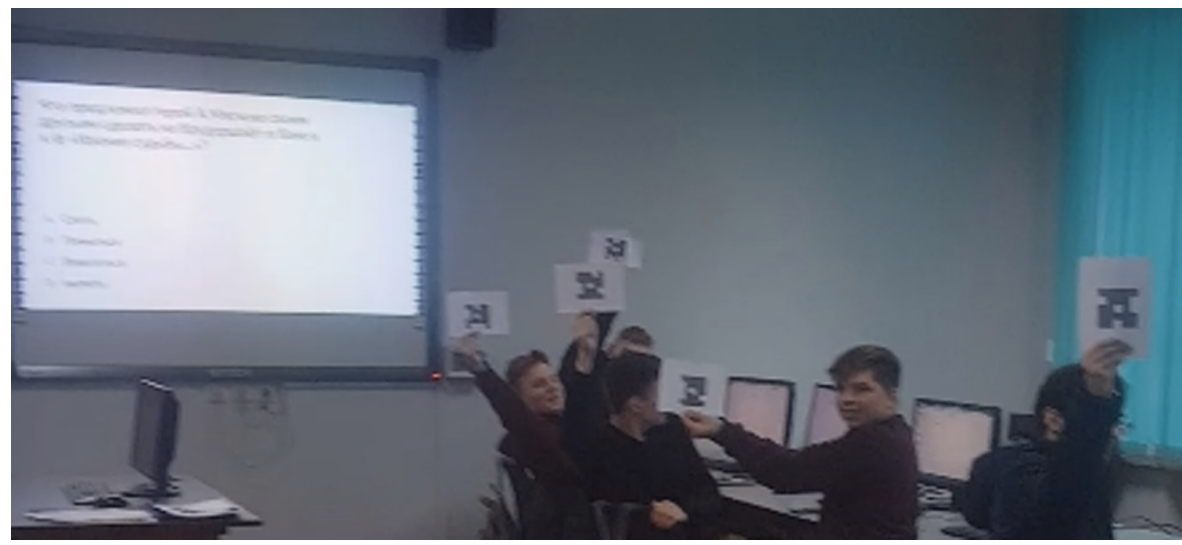

Fig. 2. Students' Plickers cards in class.

When implementing online learning in the pandemic period, methods of Plickers application have not changed much: students presents electronic pictures on their mobile Internet-devices in addition to printed ones. With that, the speed of responding has increased due to scanning pictures of similar sizes in Zoom or Google Meet.

Table 1 gives comparison of functionality of mobile tools with Audience Response Systems. Among various tools under analysis, attention should be paid to Plickers that enables combining of mobile device and augmented reality into a single multimedia environment.

\subsection{Methods of Applying Mobile Multimedia Authoring Tools}

Combination of various ways of data presentation is the core of the multimedia learning theory developed by R.E. Mayer who distinguishes four cognitive processes - choice, arrangement, transformation and integration of data [30, p. 118]. Selected text and graphical data are processed separately first. Next, selected data are arranged into two separate models for word and graphical data. While being processed, word data can be transformed into graphical ones (for example, by building mental images) and vice versa (by using internal verbalization of images). To successfully accomplish multimedia learning, both models should be integrated and associated with previously acquired knowledge [30]. 


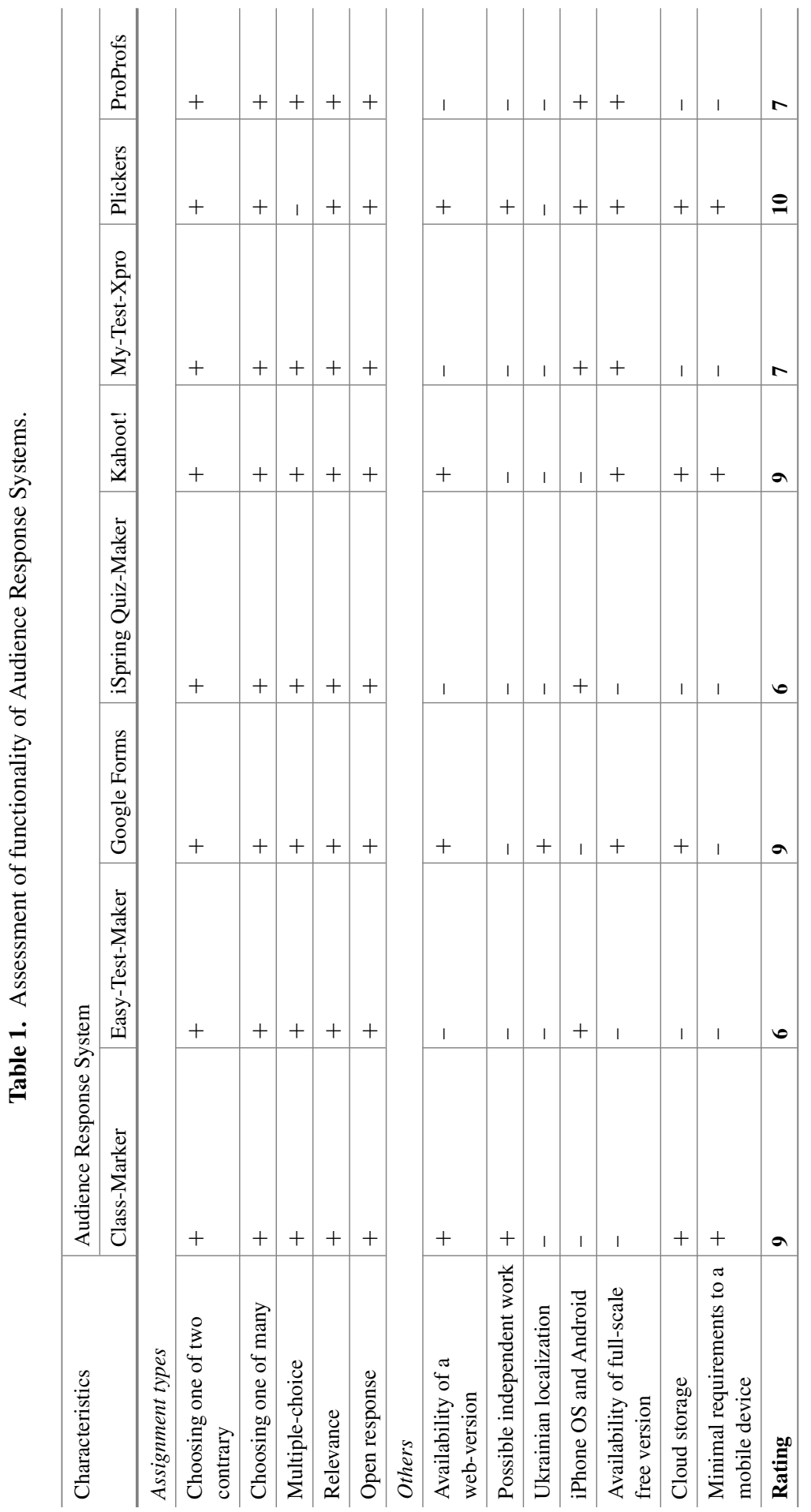


According to R.E. Mayer [29], there are three basic approaches to presenting multimedia materials:

- according to transmitting channels - by two or more devices (for example, a screen and speakers);

- according to transmitting modes - text- and graphics-based (screen texts and animation);

- according to perceptive modality - audial and visual (animation accompanied by narration).

Each of these approaches is relevant to a separate class of multimedia development tools: the first class (tools of video-data designing), the second class (presentation designing tools), and the third one (augmented reality tools including Augment, Blippar, Amazon Sumerian, Anatomy 4D, AR Flashcards Space Lite, AR Freedom Stories, AR-3D Science, Chromville, Elements 4D, HP Reveal, and Google Lens. With any approach applied, Mayer insists on the following principles of multimedia development to be guided by [29, pp. 59-60]:

1. The multimedia principle: people learn by words and images better than by words only.

2. The space vicinity principle: people learn better when corresponding words and images go together and not far from each other on a page or screen.

3. The time adjacency principle: people learn better, when corresponding words and images go simultaneously and not in succession.

4. The coherence principle: people learn better, when irrelevant words, images and sounds are off and not on.

5. The modality principle: people learn better by using animation and narration than by animation and a screen text.

6. The excessiveness principle: people learn better by using animation and narration than by animation, narration and a screen text.

7. The personalization principle: people learn better, when words are presented in spoken language than in formal one.

8. The interactivity principle: people learn better, when they control the presentation pace.

9. The signalization principle: people learn better, when words contain markers on presentation arrangement.

10. The principle of individual distinctions: multimedia effects affect low-level students better than high-level ones. Multimedia effects are more powerful for highly professional students than for low-professional ones.

Observance of these principles enables us to declare that any system in compliance with them is a mobile tools of multimedia development.

Application of Mobile Multimedia Authoring Tools allows increasing efficiency of controlling students' attention span and motivation.

Considering the fact that methods of using tools of designing videos and presentations are revealed in $[27,50,51]$, it is more reasonable to deal with Mobile Multimedia Authoring Tools in this paper. 


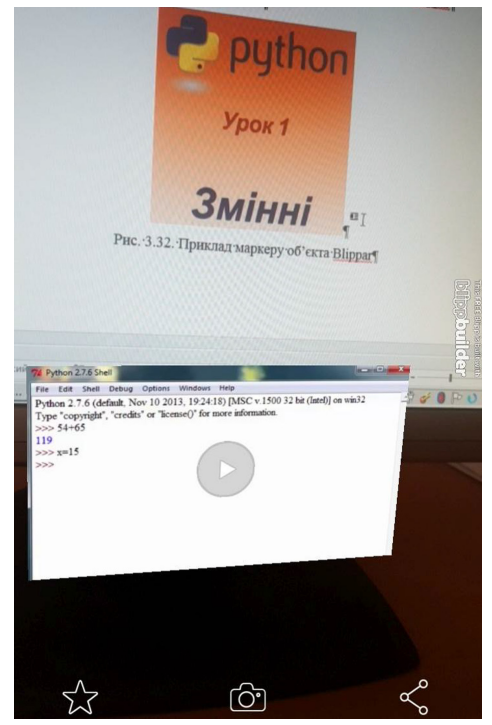

Fig. 3. The Blippar object in the AR browser Blippar.

To arrange students' activity while studying Computer Technologies in Educational Process, we apply the system Blippar [15], which enables multimedia projects of augmented reality to be implemented.

For perform a multimedia project with augmented reality in Blippar, one should get registered on their official site - https://accounts.blippar.com/signup/free.

Figure 3 shows the marker associated with the video-lesson Variables in Python language in Informatics class at Kryvyi Rih National University. After scanning the Blippar object, students download a video-lesson from YouTube.

In online learning, efficiency of applying AR-based multimedia tools has improved due to 'going beyond the screen' that creates conditions for increasing students' motion activity restricted by the current pandemic.

Table 2 gives comparison of functionality of mobile tools with augmented reality. Among various tools under analysis, attention should be paid to Amazon Sumerian that enables combining tools of virtual and augmented reality into a single multimedia environment based on the web-browser supporting WebGL 2.0 and WebXR 1.0.

\subsection{Methods of Applying Mobile Learning Management Systems}

Mobile Learning Management Systems are scientific, informational, reference materials and tools developed in the digital form and disposed in computer networks. They are reproduced by using mobile tools and required to arrange the effective educational process and use high-quality training and methodological materials. These systems facilitate learning and content management and provide for reporting without continuous Internet access. 


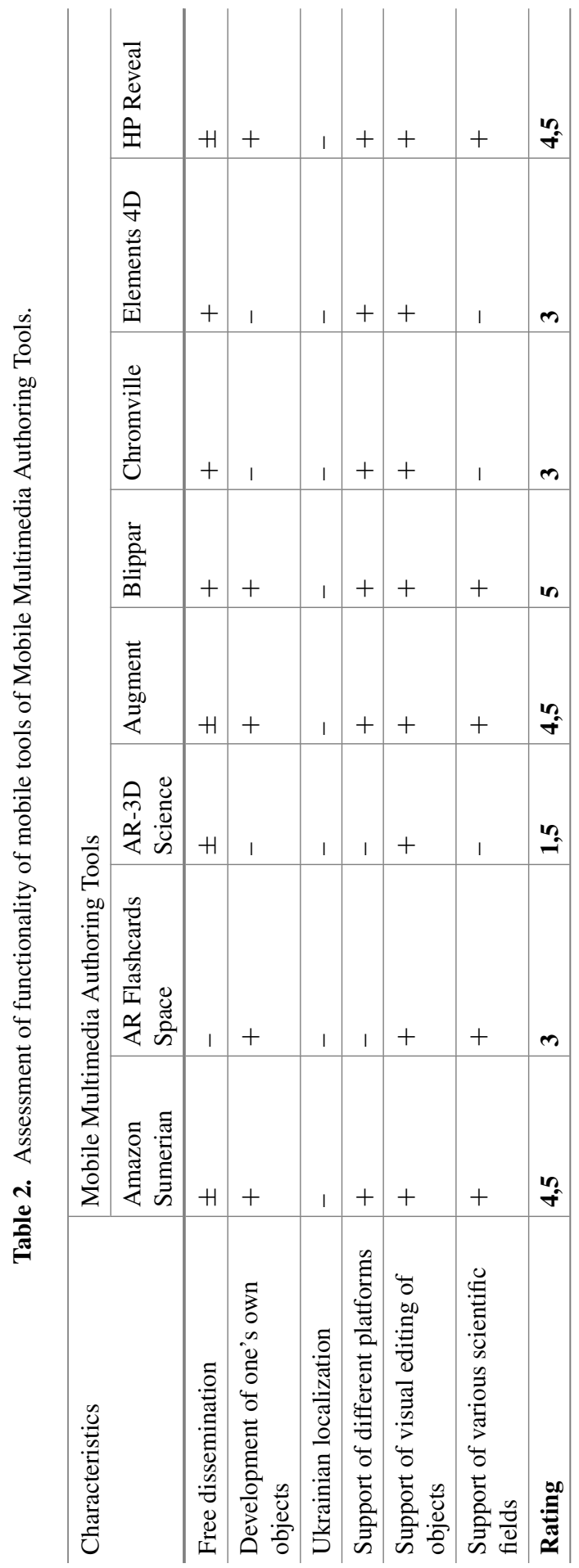


Moodle, Google Classroom, ATutor, CourseSites, EdApp, GoSkills, Sakai, Schoology, etc. are the most wide-spread free learning management systems that are actively engaged into learning support through e-academic resources.

To work with Moodle, a University teacher should get registered on the site (https:// www.moodle.com/) and create a learning course (Fig. 4 and Fig. 5).

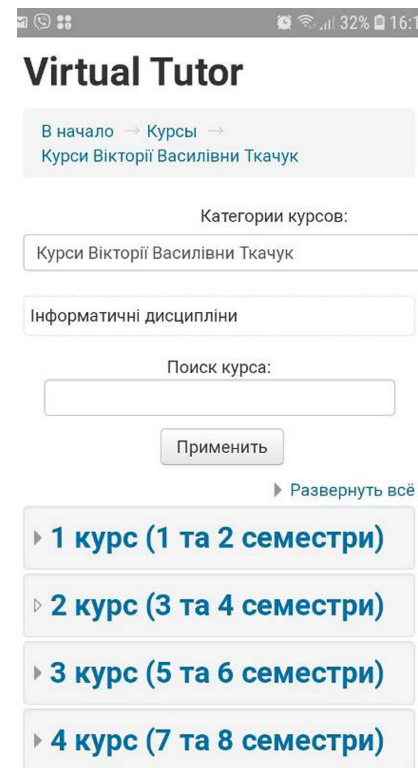

Fig. 4. Mobile courses in informatics subjects.

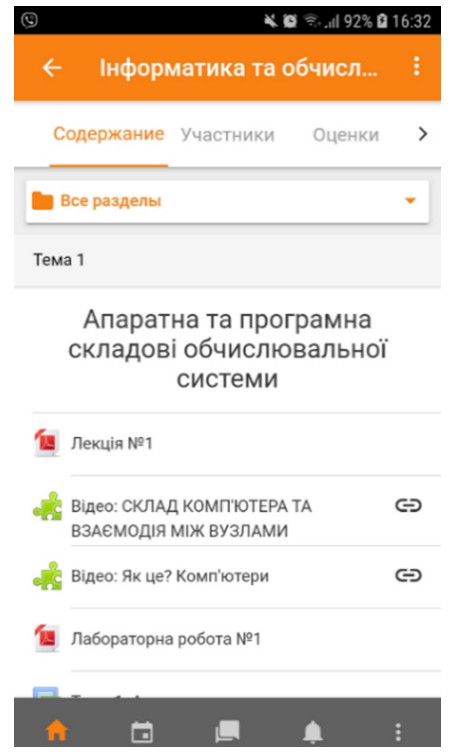

Fig. 5. The course Informatics and Computer Practical Training in Moodle.

The year that has gone since the beginning of the pandemic reveals that Mobile Learning Management Systems such as Moodle and Google Classroom have become a golden standard for creating a new mobile learning environment through uniting university teachers, students and administration to prevent destruction of the education-al process.

Table 3 gives assessment of opportunities of the most wide-spread learning management systems.

\subsection{Methods of Applying Mobile Modelling and Programming Environments}

The Mobile Modeling and Programming Environments is a software complex adapted to various operating systems and mobile devices that combines basic tools required for designing and adjusting software. The environment includes a word processor supporting syntax of a selected programming language, a compiler or an interpreter of a programming language, input and output tools, adjustment and profiling of a programming code, tools for teamwork designing, etc. 
Table 3. Assessment of functionality of mobile LMS.

\begin{tabular}{l|l|l|l|l|l|l|l|l}
\hline Characteristics & \multicolumn{9}{l}{ Mobile LMS } & \begin{tabular}{l} 
Google \\
\cline { 2 - 10 }
\end{tabular} & Moodle & ATutor & CourseSites & EdApp & GoSkills & Sakai & Schoology \\
\hline Feedback & + & \pm & + & + & + & + & + & + \\
\hline Testing, quiz & + & + & + & + & + & + & + & + \\
\hline $\begin{array}{l}\text { Ukrainian } \\
\text { localization }\end{array}$ & + & + & - & - & - & - & - & - \\
\hline Video-conference & \pm & + & \pm & - & + & - & - & - \\
\hline Calendar & + & + & + & + & + & + & + & + \\
\hline $\begin{array}{l}\text { Assessment, } \\
\text { register }\end{array}$ & + & + & \pm & + & + & + & \pm & + \\
\hline $\begin{array}{l}\text { Various task } \\
\text { types }\end{array}$ & + & \pm & + & + & + & + & + & + \\
\hline Rating & $\mathbf{6 , 5}$ & $\mathbf{6}$ & $\mathbf{5}$ & $\mathbf{5}$ & $\mathbf{5 , 5}$ & $\mathbf{5}$ & $\mathbf{4 , 5}$ & $\mathbf{5}$ \\
\hline
\end{tabular}

Mobile Modeling and Programming Environments can be integrated, modular or composed of separate components (a code editor, a compiler, an operator), each of them being installed on a mobile device. With the visualized environment, it can be accessed by one of cloud access models (usually SaaS). To support students specializing in Informatics and Computer Practical Training (the content module Fundamentals of algorithmization and programming by Python), it is reasonable to use the mobile environment Pydroid 3 - Educational IDE for Python 3.

Basic advantages of using this environment for teaching informatics-related subjects include:

- no need to have permanent Internet access;

- a built-in manager of pip-packages;

- a full-scale terminal emulator;

- built-in compilers of the languages $\mathrm{C}, \mathrm{C}++$ and Fortran;

- support of the operator PDV;

- a code editor with autcompletion and syntax highlighting;

- exchange of code fragments through Pastebin.

Pydroid can be adjusted to a user's needs by using corresponding menu elements. Then according to the laboratory work task, students input a code, compile it and see the results (Fig. 6).

The pandemic period activates the potential of these environments for organizing communication, distance activity and mutual editing, this accentuating web-based environments based on Jupyter Notebok such as CoCalc and Google Colab.

Table 4 presents general assessment of functionality of Mobile Modeling and Programming Environments. 


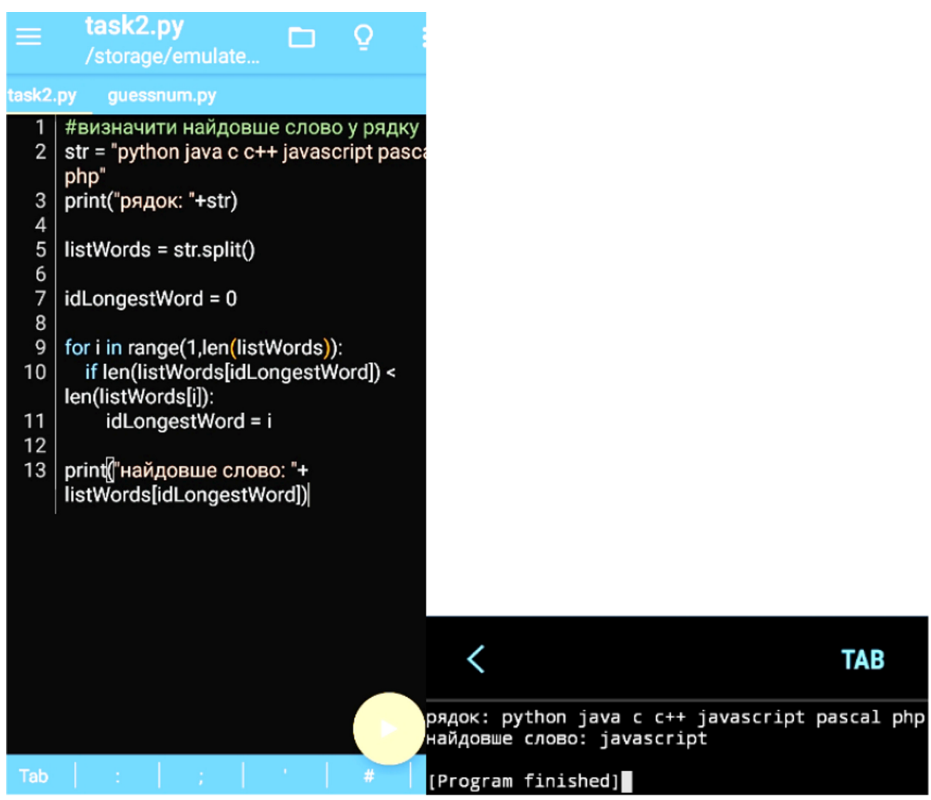

Fig. 6. Solving a problem in Pydroid.

\subsection{Methods of Applying Mobile Database Management Systems}

The DBMS (Database Management System) is a system software for designing and controlling databases that enable users and programmers to design, create, obtain, update and control data systematically [43].

The mobile database management system is the DBMS with the client access to the server provided by mobile interfaces and/or mobile Internet devices.

To access the mobile DBMS via Google Cloud SQL, it is necessary to use a version with a yearly free access. This service is provided to both relational (Amazon Aurora, Google Cloud SQL, Oracle Database Cloud Service, Microsoft Azure SQL Database) and nonrelational (Amazon DynamoDB, Azure Cosmos DB, Google Cloud Datastore, Oracle NoSQL Database Cloud Service) DBMS.

While studying the DBMS in the content module Software of Computing Systems, students work in the mobile client environment MySQL. To start MySQL, a teacher adjusts a cloud server and downloads templates of databases. The earlier downloaded database classic models are composed of the following tables (Fig. 7):

- customers: stores a client's data;

- products: stores a list of car makes;

- productlines: stores a list of product lines;

- orders: stores a client's orders;

- orderdetails: stores lines of sale orders for each client's order;

- payments: stores payments from clients on the basis of calculations; 


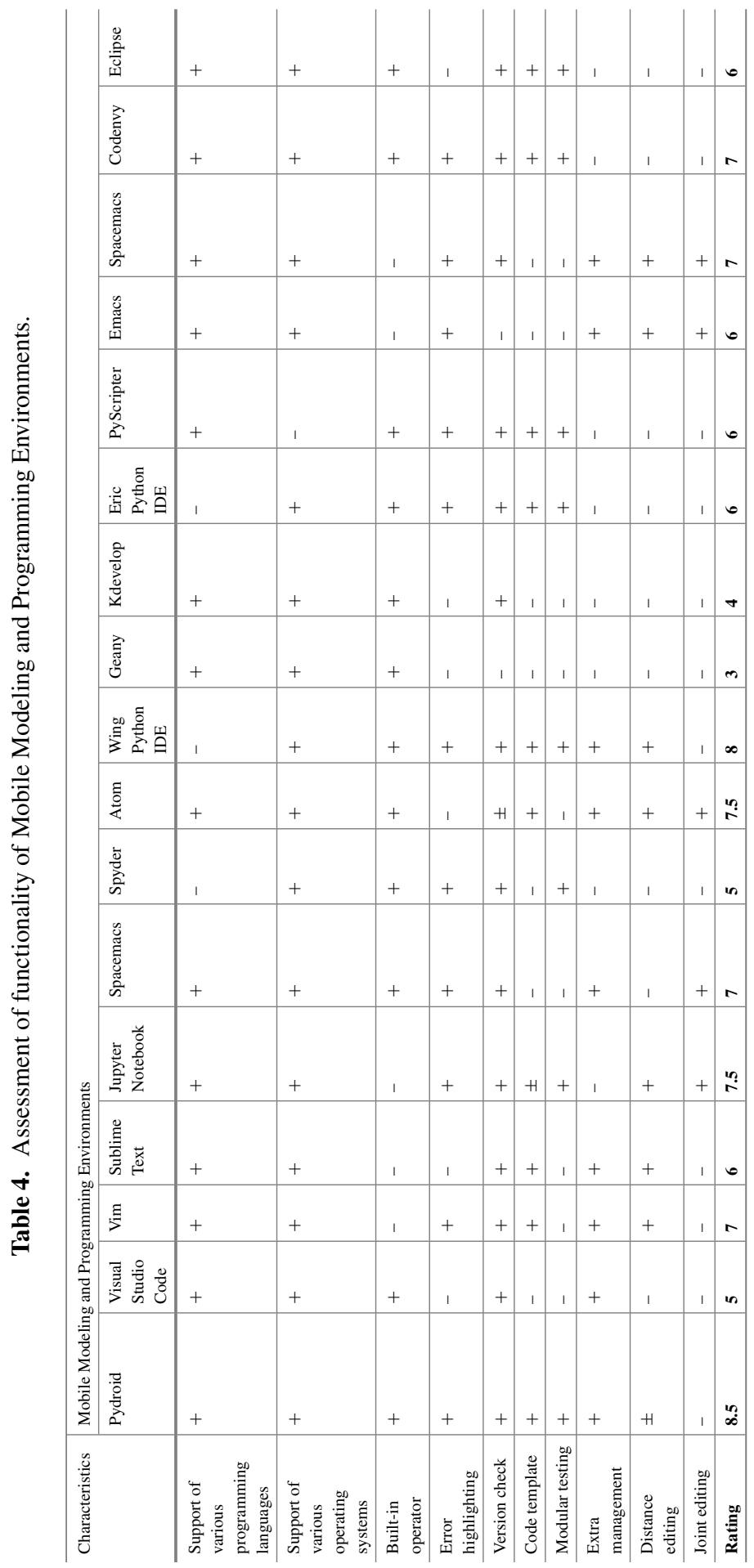


- employees: stores all the data on employees and a company's structure;

- offices: stores data of the sales department.

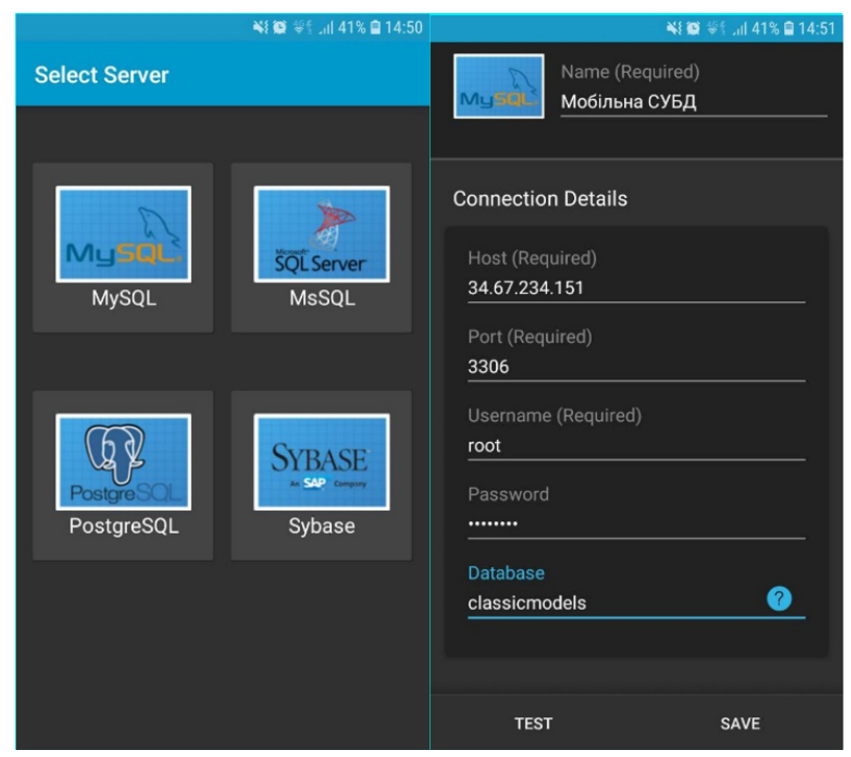

Fig. 7. The initial screen of Google Cloud SQL.

Considering the fact that the work with the server part of cloud DBMS is performed via mobile clients, functionality of mobile systems of database management is assessed by comparing client characteristics (Table 5).

\section{Results of Experimental Examination of the Suggested Methods}

The first-fourth year students of Kryvyi Rih National University (the Faculty of Information Technologies), Kryvyi Rih State Pedagogical University (the Faculty of Physics and Mathematics) and the Separated Structural Subdivision "Kryvyi Rih Professional College of National Aviation University" (the Faculty of Information Technologies) took part in the experiment in the 2020-2021 academic year during the COVID-19 lockdown with 176 17-21 year old students engaged. Engineering students were involved in the experiment including 87 students of the experiment group and 89 students of the control group. The knowledge level defined either by examinations or the external entrance tests (the first year students) became a criterion for selecting students for the control and experiment groups.

The experiment aimed to determine efficiency of applying mobile ICT to online learning during the COVID-19 lockdown by assessing the formation level of IC-competences. 


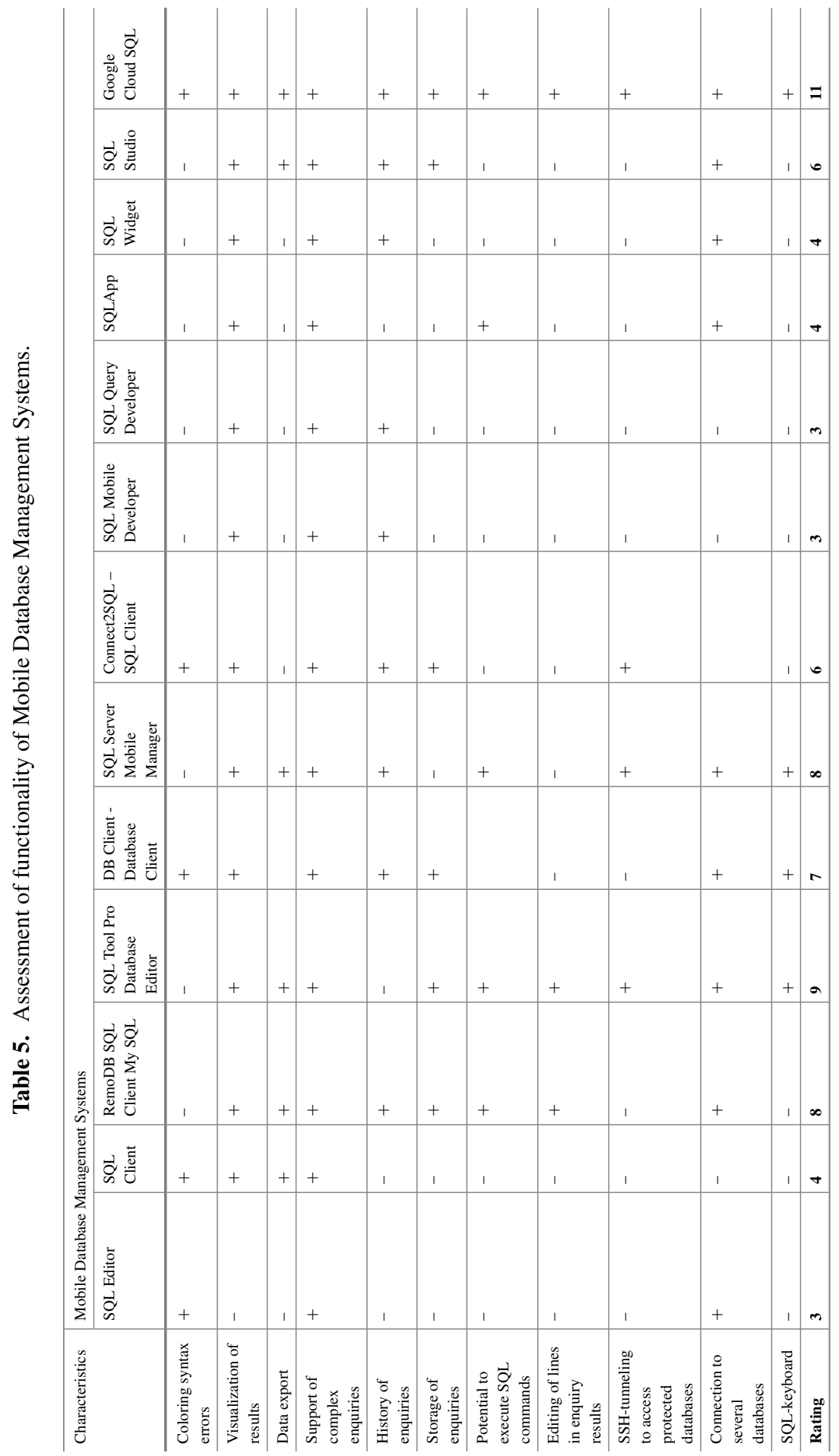


Table 6. Efficiency criteria of applying mobile technologies in university classrooms.

\begin{tabular}{l|l|l|l}
\hline \multicolumn{2}{l|}{ Criterion } & Levels of formation & Research methods \\
\hline $1^{\text {st }}$ & $\begin{array}{l}\text { Competencies of using Mobile Learning } \\
\text { Management Systems }\end{array}$ & High; medium; low & Matrix of Competencies \\
\hline $2^{\text {nd }}$ & $\begin{array}{l}\text { Competencies of using Mobile Modeling and } \\
\text { Programming Environments }\end{array}$ & High; medium; low & \\
\cline { 1 - 2 } $3^{\text {rd }}$ & $\begin{array}{l}\text { Competencies of using Mobile Database } \\
\text { Management Systems }\end{array}$ & \multirow{2}{*}{ High; medium; low } & \\
\hline $4^{\text {th }}$ & $\begin{array}{l}\text { Competencies of using Mobile Multimedia } \\
\text { Authoring Tools }\end{array}$ & High; medium; low & \\
\cline { 1 - 2 } $5^{\text {th }}$ & $\begin{array}{l}\text { Competencies of using Audience Response } \\
\text { Systems }\end{array}$ & High; medium; low & \\
\hline
\end{tabular}

Table 7. Experimental results.

\begin{tabular}{|c|c|c|c|c|c|}
\hline \multirow[t]{2}{*}{ Criterion } & \multirow[t]{2}{*}{ Levels } & \multicolumn{2}{|l|}{ Control group } & \multicolumn{2}{|l|}{ Experiment group } \\
\hline & & Number of students & $\%$ & Number of students & $\%$ \\
\hline \multirow{4}{*}{$\begin{array}{l}\text { Competencies of using Mobile } \\
\text { Learning Management Systems }\end{array}$} & High & 14 & 15,73 & 18 & 20,69 \\
\hline & Medium & 50 & 56,18 & 55 & 63,22 \\
\hline & Low & 25 & 28,09 & 14 & 16,09 \\
\hline & Total & 89 & 100 & 87 & 100 \\
\hline \multirow{4}{*}{$\begin{array}{l}\text { Competencies of using Mobile } \\
\text { Modeling and Programming } \\
\text { Environments }\end{array}$} & High & 11 & 12,36 & 19 & 21,84 \\
\hline & Medium & 55 & 61,80 & 55 & 63,22 \\
\hline & Low & 23 & 25,84 & 13 & 14,94 \\
\hline & Total & 89 & 100 & 87 & 100 \\
\hline \multirow{4}{*}{$\begin{array}{l}\text { Competencies of using Mobile } \\
\text { Database Management Systems }\end{array}$} & High & 14 & 15,73 & 22 & 25,29 \\
\hline & Medium & 54 & 60,67 & 50 & 57,47 \\
\hline & Low & 21 & 23,60 & 15 & 17,24 \\
\hline & Total & 89 & 100 & 87 & 100 \\
\hline \multirow{4}{*}{$\begin{array}{l}\text { Competencies of using Mobile } \\
\text { Multimedia Authoring Tools }\end{array}$} & High & 10 & 11,24 & 16 & 18,39 \\
\hline & Medium & 57 & 64,04 & 56 & 64,37 \\
\hline & Low & 22 & 24,72 & 15 & 17,24 \\
\hline & Total & 89 & 100 & 87 & 100 \\
\hline \multirow{4}{*}{$\begin{array}{l}\text { Competencies of using } \\
\text { Audience Response Systems }\end{array}$} & High & 12 & 13,48 & 20 & 22,99 \\
\hline & Medium & 55 & 61,80 & 53 & 60,92 \\
\hline & Low & 22 & 24,72 & 14 & 16,09 \\
\hline & Total & 89 & 100 & 87 & 100 \\
\hline
\end{tabular}


The experiment group used mobile ICT (Audience Response Systems, Mobile Learning Management Systems, Mobile Modeling and Programming Environments, Mobile Database Management Systems, Mobile Multimedia Authoring Tools), while the control one used various tools depending on teachers' IC-competences.

The mobile ICT tools were used in the following way: students of the experiment group used Mobile Learning Management Systems, Audience Response Systems, Mobile Multimedia Authoring Tools as these systems were of general application designated for studying any subjects. Yet, Mobile Modeling and Programming Environments, Mobile Database Management Systems were applied only to studying specific vocation-related subjects for the third-fourth year students.

To examine the method, we determine efficiency criteria of applying mobile technologies in university classrooms, their indices and research methods (Table 6). The research is based on experimental studies.

To monitor competency formation and diagnostics of its formation level, competency matrices were used. To assess the formation level of each competency, the content of relevant IC-competences was set and a corresponding matrix was designed. Assessment methods of the formation level of competences were described in our study [46].

The number of students of the experiment group with high and medium levels is larger than that of the control group by the 1 st criteria $-12,00 \%$, by the 2 nd criteria $-10,90 \%$, by the 3 rd criteria $-6,36 \%$, by the 4 th criteria $-7,48 \%$, by the 5 th criteria $-8,63 \%$ (Table 7).

After generalizing the results of the pedagogical experiment, we can conclude that the developed methods of applying mobile technologies to online learning are quite efficient, especially during the COVID-19 lockdown. The total experimental results are given in Fig. 8.

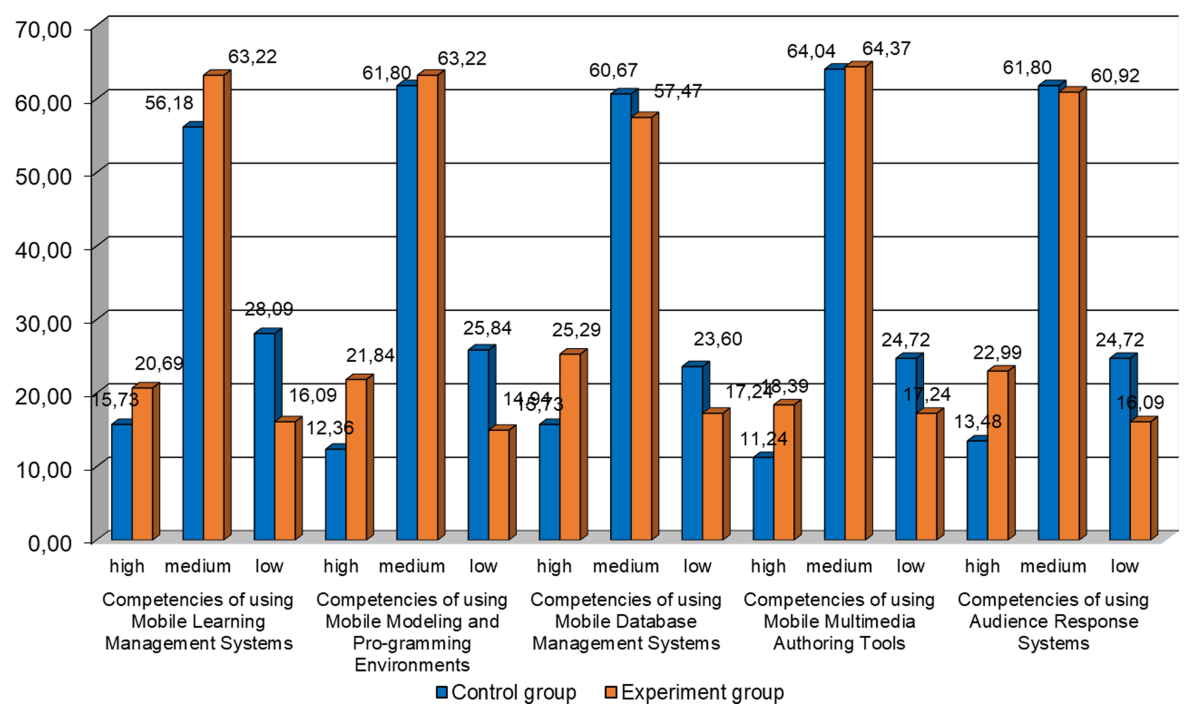

Fig. 8. Generalized results of the experiment. 


\section{Conclusions}

While investigating into potentials of mobile technologies used by students in online learning during the COVID-19 lockdown, we obtained the following results:

- it is determined that online learning is a leading technology for providing education in Ukraine and abroad during the lockdown;

- Ukrainian and foreign researches into the issues of mobile technology application to online learning are analyzed;

- to select the most effective mobile ICT, their functionality is assessed. Five leading groups of mobile ICT that cover all the aspects of distance learning are selected. In each group, mobile ICT tools are compared by several criteria and the most efficient are selected (Plickers, Moodle, Pydroid, Google Cloud SQL, Blippar);

- the following methods of teaching informatics subjects by using Mobile ICT tools are implemented: Audience Response Systems (using Plickers as an example), Mobile Learning Management Systems (using Moodle as an example), Mobile Modeling and Programming Environments (using Pydroid as an example), Mobile Database Management Systems (using Google Cloud SQL as an example), Mobile Multimedia Authoring Tools (using Blippar as an example);

- efficiency of the developed methods is experimentally verified and confirmed, namely the results of the "Competencies of using Mobile Learning Management Systems" criterion increased by $4,96 \%$ at the high level and by $7,04 \%$ on average; the results of the "Competencies of using Mobile Modeling and Programming Environments" criterion increased by $9,48 \%$ at the high level and by $1,42 \%$ on average; the results of the "Competencies of using Mobile Database Management Systems" criterion increased by $9,56 \%$ at the high level and by $3,20 \%$ on average; the results of the "Competencies of using Mobile Multimedia Authoring Tools" criterion increased by $7,15 \%$ at the high level and by $0,32 \%$ on average; the results of the "Competencies of using Audience Response Systems" criterion increased by 9,51\% at the high level and by $0,88 \%$ on average.

Online learning is essential for both students and lecturers, so universities should exert every effort to discover the optimal way of reaching the best learning outcomes especially during the COVID-19 lockdown. To do this, we suggest a wider application of:

- AR tools that enable increasing students' motion activity by combining various learning stages: this helps mitigate consequences of movement constraints;

- communication tools and joint activity on ICT-projects in modeling, programming and database design: this helps mitigate consequences of social communication constraints;

- machine learning tools in Learning Management Systems aimed at the algorithm forecasting of learning results through monitoring students' activity: this eliminates destruction of the educational process. 
The current pandemic actualizes the university's function of being the students' socialization environment in the educational process. Thus, developing the immersive cloud-based learning environment as an open multidimensional technological and pedagogical system which comprises mobile ICT, VR/AR technologies and ensures interaction, cooperation, development of university teachers, students and administration while solving educational, technological and scientific problems anytime and anyplace.

\section{References}

1. Abu-Al-Aish, A.: Toward mobile learning deployment in higher education. Ph.D. thesis, Brunel University (2011)

2. Altayeb, B., Damevski, K.: Utilizing and enhancing software modeling environments to teach mobile application design. J. Comput. Sci. Coll. 28(6), 57-64 (2013). https://doi.org/10.5555/ 2460156.2460168

3. Baharom, S.S.: Designing mobile learning activities in the Malaysian HE context: a so-cial constructivist approach. Ph.D. thesis, University of Salford (2013)

4. Billington, C.: Psychosocial influences on the use and regulation of mobile phones in high schools. Perspectives from pupils, teachers and parents, an exploratory case study approach. Dissertation, University of Birmingham (2011)

5. Bird, P.W.: Potentially disruptive IS innovation in UK higher education institutions: an actor-network theory analysis of the embedding of m-learning. Ph.D. thesis, Manchester Metropolitan University (2014)

6. Blaschke, L.M., Bedenlier, S.: Online learning. In: Oxford Research Encyclopedia of Education. Oxford Publications, Oxford (2020)

7. Bykov, V.: Mobilnyi prostir i mobilno oriientovane seredovyshche internet-korystuvacha: osoblyvosti modelnoho podannia ta osvitnoho zastosuvannia (The mobile space and mobile targeting environment for internet users: features of model submission and using in education). Inf. Technol. Educ. 17, 9-37 (2013). https://doi.org/10.14308/ite000445

8. Chan, N.N.: Learning with smartphones: a hermeneutic phenomenological study of young people's everyday mobile practices. Dissertation, University of Durham (2013)

9. Chan, T.F.I., Borja, M., Welch, B., Batiuk, M.E.: Predicting the probability for faculty adopting an audience response system in higher education. J. Inf. Technol. Educ. Res. 15, 395-407 (2016)

10. Chiappe, A.: Understanding mobile educational content. J. Educ. Media Mem. Soc. 10(2), 1-19 (2018). https://doi.org/10.3167/jemms.2018.100201

11. Bakhtiar, M.S., Choudhary, A.B., Choudary, S.J., Kumar, R., Jamal, S.: The impact of ergonomics on children studying online during COVID-19 lockdown. J. Adv. Sports Phys. Educ. 3(8), 117-120 (2020). https://doi.org/10.36348/jaspe.2020.v03i08.001

12. Colleges, Universities, and Higher Learning: Plan, Prepare and Respond - COVID-19. U.S. Department of Health \& Human Services (2020). https://www.cdc.gov/coronavirus/2019ncov/community/colleges-universities/index.html. Accessed 22 Jan 2021

13. Coronavirus (COVID-19) information for higher education providers. The Department of Education, Skills and Employment of Australian Government (2020). https://www.dese.gov. au/covid-19/higher-education. Accessed 22 Jan 2021

14. Coronavirus: Online learning resources: Discover a selection of online resources and tools for learners, teachers and educators during the outbreak of COVID-19. European Commission (2020). https://ec.europa.eu/education/resources-and-tools/coronavirus-online-learningresources_en. Accessed 22 Jan 2021 
15. Create \& Make augmented reality using Blippbuilder tools - Blippar. Computer Vision Company I Blippar (2019). https://web.blippar.com/blipp-builder\#Blippbuilder. Accessed 28 Oct 2019

16. Erić, M., Mitrović, S., Stefanović, M., Đorđević, A.: Tribology database as platform for mobile database and use of mobile technologies. Tribol. Ind. 38(2), 267-275 (2016)

17. Fotouhi-Ghazvini, F.: Mobile learning using mixed reality games and a conversational, instructional and motivational paradigm: design and implementation of technical language learning mobile games for the developing world with special attention to mixed reality games for the realization of a conversational, instructional and motivational paradigm. Ph.D. thesis, University of Bradford (2011)

18. Gezgin, D.M.: The effect of mobile learning approach on university students' academic success for database management systems course. Int. J. Distance Educ. Technol. 17(1), 15-30 (2019). https://doi.org/10.4018/IJDET.2019010102

19. Guidance on distance learning modalities to reach all children and youth during school closures. UNICEF Regional Office for South Asia (2020). https://www.unicef.org/rosa/ media/7996/file/Guidance\%20Continuity\%20of\%20Learning\%20during\%20COVID-19\% 20-\%20Reaching\%20All\%20Children_UNICEF\%20ROSA.pdf. Accessed 22 Jan 2021

20. Guo, M., Qian, K., Yang, L.: Hands-on labs for learning mobile and NoSQL database security. In: IEEE 40th Annual Computer Software and Applications Conference (COMPSAC), Atlanta, GA, 2016, vol. 2, pp. 606-607. IEEE (2016). https://doi.org/10.1109/COMPSAC. 2016.126

21. Han, I., Shin, W.S.: The use of a mobile learning management system and academic achievement of online students. Comput. Educ. 102, 79-89 (2016). https://doi.org/10.1016/j.com pedu.2016.07.003

22. Helping children and young people while they are learning at home. New Zealand Ministry of Education (2020). https://www.education.govt.nz/school/health-safety-and-wellbeing/pas toral-care-and-wellbeing/talking-to-children-about-covid-19-coronavirus/. Accessed 22 Jan 2021

23. Hepburn, M.: Investigating the potential for new media and new technologies in design and technology undergraduate education. Ph.D. thesis, Loughborough University (2012)

24. Jantjies, E.M.: A framework to support multilingual mobile learning: a South African perspective. Ph.D. thesis, University of Warwick (2014)

25. Jotham, V.: iSpace? Identity \& space - a visual ethnography with young people and mobile phone technologies. Dissertation, University of Manchester (2012)

26. Kapur, R.: The significance of ICT in education (2019). https://www.researchgate.net/public ation/333198386_The_Significance_of_ICT_in_Education. Accessed 30 Mar 2021

27. Kiv, A.E., Shyshkina, M.P., Semerikov, S.O., Striuk, A.M., Yechkalo, Yu.V.: AREdu 2019 how augmented reality transforms to augmented learning. In: CEUR Workshop Proceedings, vol. 2547, pp. 1-12 (2019). http://www.ceur-ws.org/Vol-2547/paper00.pdf. Accessed 11 Jan 2020

28. Lordan Gomis, F.J.: Programming models for mobile environments. Ph.D. thesis, Universitat Politècnica de Catalunya (2018)

29. Mayer, R.E.: Multimedia learning (2008). http://ateneu.xtec.cat/wikiform/wikiexport/_ media/cursos/tic/d206/modul_1/multimedialearningmayer.pdf. Accessed 17 Dec 2019

30. Mayer, R.E.: Multimedia Learning, 2nd edn. Cambridge University Press, New York (2009)

31. Mishra, L., Gupta, T., Shree, A.: Online teaching-learning in higher education during lockdown period of COVID-19 pandemic. Int. J. Educ. Res. Open 1, 100012 (2020). https://doi. org/10.1016/j.ijedro.2020.100012 
32. Moorleghen, D.M., Oli, N., Crowe, A.J., Liepkalns, J.S., Self, C.J., Doherty, J.H.: Impact of automated response systems on in-class cell phone use. Biochem. Mol. Biol. Educ. 47(5), 538-546 (2019). https://doi.org/10.1002/bmb.21257

33. Perusso, A., Diriba, H.: Online learning toolkit. https://www.researchgate.net/publication/ 344363605_Online_Learning_Toolkit (2020). Accessed 22 Jan 2021

34. Restricting attendance during the national lockdown: schools. Guidance for all schools in England (2021). https://assets.publishing.service.gov.uk/government/uploads/system/upl oads/attachment_data/file/952443/210114_School_national_restrictions_guidance_FINAL_ 14012021.pdf. Accessed 22 Jan 2021

35. Rizun, N.O., Taranenko, Y.K.: Mobilna systema komp'iuternoho testuvannia yak instrument intensyfikatsii navchalnoho protsesu VNZ (Mobile system of computer testing as the instrument of intensification of study process in higher education institutions). Radio Electron. Comput. Sci. Control 1, 129-134 (2012). https://doi.org/10.15588/1607-3274-2012-1-24

36. Salzer, R.: Smartphones as audience response systems for lectures and seminars. Anal. Bioanal. Chem. 410(6), 1609-1613 (2018). https://doi.org/10.1007/s00216-017-0794-8

37. Santos, J., Parody, L., Ceballos, M., Alfaro, M.C., Trujillo-Cayado, L.A.: Effectiveness of mobile devices as audience response systems in the chemistry laboratory classroom. Comput. Appl. Eng. Educ. 27(3), 572-579 (2019). https://doi.org/10.1002/cae.22098

38. Sanz-Martínez, L., Er, E., Martínez-Monés, A., Dimitriadis, Y., Bote-Lorenzo, M.L.: Creating collaborative groups in a MOOC: a homogeneous engagement grouping approach. Behav. Inf. Technol. 38(11), 1107-1121 (2019). https://doi.org/10.1080/0144929X.2019.1571109

39. Schlücker, S.: Das Smartphone - ein Antwortgerät. Nachr. Chem. 65(2), 164-166 (2017). https://doi.org/10.1002/nadc.20174054959

40. Semerikov, S.O.: Teoretyko-metodychni osnovy fundamentalizatsii navchannia informatychnykh dystsyplin u vyshchykh navchalnykh zakladakh. Dissertation, National Pedagogical Dragomanov University (2009)

41. Shao, Y.: Mobile group blogging in learning: a case study of supporting cultural transition. Ph.D. thesis, University of Nottingham (2010)

42. Striuk, A.M., Rassovytska, M.V., Shokaliuk, S.V.: Using Blippar augmented reality browser in the practical training of mechanical engineers. In: CEUR Workshop Proceedings, vol. 2104, pp. 412-419 (2018). http://ceur-ws.org/Vol-2104/paper_223.pdf. Accessed 29 Feb 2020

43. Sutar, A., Bhosale, S., Pujari, V.: ICT in education system (2019). https://www.researchgate. net/publication/336579627_ICT_IN_EDUCATION_SYSTEM. Accessed 30 Mar 2021

44. Tjondronegoro, D. (ed.): Tools for Mobile Multimedia Programming and Development. IGI Global, Hershey (2013)

45. Tkachuk, V., Semerikov, S., Yechkalo, Y., Khotskina, S., Soloviev, V.: Selection of mobile ICT for learning informatics of future professionals in engineering pedagogy. In: CEUR Workshop Proceedings, vol. 2732, pp. 1058-1068 (2020). http://ceur-ws.org/Vol-2732/202 01058.pdf. Accessed 30 Mar 2021

46. Tkachuk, V.V.: Diagnostics of the level formation ICT-competencies future engineerspedagogs of the computer profile. Naukovi zapysky. Seriia: Problemy metodyky fizykomatematychnoi i tekhnolohichnoi osvity 2(11), 205-212 (2017). https://phm.cuspu.edu.ua/ ojs/index.php/NZ-PMFMTO/article/download/1171/1150. Accessed 30 Mar 2021

47. Trinder, J.J.: Mobile learning evaluation: the development of tools and techniques for the evaluation of learning exploiting mobile devices through the analysis of automatically collected usage logs - an iterative approach. Ph.D. thesis, University of Glasgow (2012)

48. Vchymo i navchaiemos na karantyni: zminy v systemi osvity. Ministry of Education and Science of Ukraine (2021). https://mon-covid19.info. Accessed 22 Jan 2021 
49. Wali, E.A.: Reinterpreting mobile learning: an activity theoretic analysis of the use of portable devices in higher education. Ph.D. thesis, University of London (2008)

50. Yechkalo, Y.V., Tkachuk, V.V., Hruntova, T.V., Brovko, D.V., Tron, V.V.: Augmented reality in training engineering students: teaching techniques. In: CEUR Workshop Proceedings, vol. 2393, pp.952-959 (2019). http://ceur-ws.org/Vol-2393/paper_337.pdf. Accessed 13 Feb 2020

51. Yechkalo, Y.V.: Methodological basis of the creation of new type educational and methodical complex of physics for students of higher educational institutions. Collection of Scientific papers Kamianets-Podilskyi National Ivan Ohiienko University. Pedagogical series, vol. 20, pp. 16-18 (2014). https://doi.org/10.32626/2307-4507.2014-20.16-18 